\title{
ATYPICAL CASE OF RETAINED INTRAOCULAR FOREIGN BODY PRESENTING AS SECONDARY GLAUCOMA AFTER 12 YEARS
}

Chandrakant Pujar1, Narayan M², Sai Sushma33, Prabhu4, Padmini ${ }^{5}$

\section{HOW TO CITE THIS ARTICLE:}

Chandrakant Pujar, Narayan M, Sai Sushma, Prabhu, Padmini. "Atypical Case of Retained Intraocular Foreign Body Presenting as Secondary Glaucoma after 12 Years". Journal of Evolution of Medical and Dental Sciences 2015; Vol. 4, Issue 13, February 12; Page: 2223-2227, DOI: 10.14260/jemds/2015/320

ABSTRACT: Atypical case of retained intraocular foreign body presenting as secondary glaucoma after 12 years. To report a case of retained intraocular foreign body presenting as glaucoma after 12 yrs. A 24 yrs old male patient came to OPD, with pain \& redness in right eye since 2 days. He was operated for cataract 12 years back. On examination, OD VA- hand movements. Slit lamp examination revealed corneal edema and deep anterior chamber. Rest of the details was not clear. OS Findings were normal. IOP: OD- $50 \mathrm{mmHg}$, OS-16 mmHg. After control of IOP with medications, following findings were noted: Corneal scar in paracentral zone. RAPD present in right eye. Iris hole present at 3'0 clock position. FUNDUS: Vitreous is clear. Intraocular foreign body of size half disc diameter present over the optic disc. Disc is pale, with attenuated vessels \& peripapillary pigmentary changes. Yellowish speckled lesions present surrounding the vessels and dull foveal reflex. Gonioscopy revealed open angles with increased pigmentation. Visual fields showing advanced field defects. CT \& B scan showing radio opaque foreign body over disc. Electro retinogram of right eye showing reduced response to all stimuli. Removal of foreign body not done because of poor visual prognosis \& risk of symphathetic ophthalmitis. CONCLUSION: Retained metallic Intraocular foreign body can manifest after many years with varied presentation like secondary glaucoma without classical features of siderosis bulbi.

KEYWORDS: Glaucoma, Siderosis.

INTRODUCTION: Penetrating ocular trauma is an important cause of vision loss and may be associated with the presence of an intraocular foreign body. Intraocular foreign bodies accompany $18 \%-41 \%$ of open globe injuries ${ }^{1}$.Hammering, machine tools, shooting weapons and being in proximity to explosions are the most common mechanisms involved in retained intraocular foreign body cases. Roughly $90 \%$ of projectile foreign bodies are metallic and over $50 \%$ are magnetic. ${ }^{2,3}$

Retained foreign bodies can cause infection and inflammation in the affected eye even years after the initial insult, however some intraocular foreign bodies can be retained without symptoms. Here we report a case of retained foreign body presenting with secondary glaucoma after 12 years.

CASE: A 24 years old male patient presented with sudden onset of pain in his right eye associated with reduced vision since 2 days. Biomicroscopic examination revealed congestion of the eye with diffuse corneal edema, visual acuity of hand movements, IOP on applanation was $54 \mathrm{mmHg}$. Left eye examination was normal.2 days after controlling IOP with medications revealed the following findings:

Visual acuity of finger counting at $1 \mathrm{M}$ with no pin hole improvement. A corneal scar at 3 clock meridian in the paracentral zone, full thickness iris defect at the same position, normal iris pattern, pupil $3 \mathrm{~mm}$ round reactive with RAPD, posterior chamber IOL. On dilated fundus examination media 


\section{CASE REPORT}

was clear and showed optic disc pallor with a brown coloured foreign body like lesion of the size of half disc diameter with peripapillary pigmentation, attenuated vessels and diffuse yellow pigmentary flecks throughout the fundus. IOP was $28 \mathrm{mmHg}$, gonioscopy showed open angles with increased pigmentation compared to the left eye angle improvement. Patient revealed that he had sustained an ocular injury 12 years back while hammering work and was operated for traumatic cataract after few months.

Perimetry showed advanced field defects. CT scan confirmed the presence of a radio opaque foreign body over the disc. Full field ERG showed reduced response to all stimuli.

DISCUSSION: Retention of metallic intraocular foreign bodies can lead to damage to ocular structures. The two most concerning culprits are iron and copper. Siderosis bulbi as a result of iron retention is characterized by rust coloured corneal stroma, iris heterochromia, mydriasis, decreased vision, lenticular deposits, cataract, retinal degeneration and glaucoma. ${ }^{4}$ In siderosis, deposition of iron in intraocular tissue results in toxicity, formation of powerful oxidants cause cell membrane damage and enzyme inactivation. Epithelial cells, RPE and photoreceptors are especially susceptible. In our case features of siderosis like iris heterochromia, mydriasis, corneal rusting was absent except for secondary open angle glaucoma and retinal degeneration. The etiopathogenesis of secondary open angle glaucoma has been attributed to trabecular fibrosclerosis probably because of direct effect of toxic iron ions. ${ }^{5}$ Shiar $\mathrm{K}$ et al has described cases of retained intraocular foreign body with no signs of siderosis but manifestation of secondary open angle glaucoma ${ }^{6}$.Retained metallic intraocular foreign body can manifest after many years and with varied presentation without all classical features of siderosis bulbi.

\section{REFERENCES:}

1. Mester V, Kuhn F: Intraocular foreign bodies, ophthalmology clinics of North America 2002: 15(2) 1235-242.

2. Williams DF, Mieler WF, Abrams GW, Lewis H, Results and prognostic factors in penetrating ocular injuries with retained intraocular foreign bodies,ophthalmology:1988; (95); 911-916.

3. Khani SC, Mukai S; Posterior segment intraocular foreign bodies; international ophthalmology clinics; 1995 (35); 151-161.

4. Hope, Ross Mahon GT, Johnston PB; Ocular siderosis; Eye; 7; 419-25.

5. Appel I, Barishak YR; Histopathological changes in siderosis bulbi; ophthalmologica, 176; 20510.

6. Zhonghua yan Ke Za Zhi, 1994, NOV, 30; (6), 420-2. 


\section{CASE REPORT}
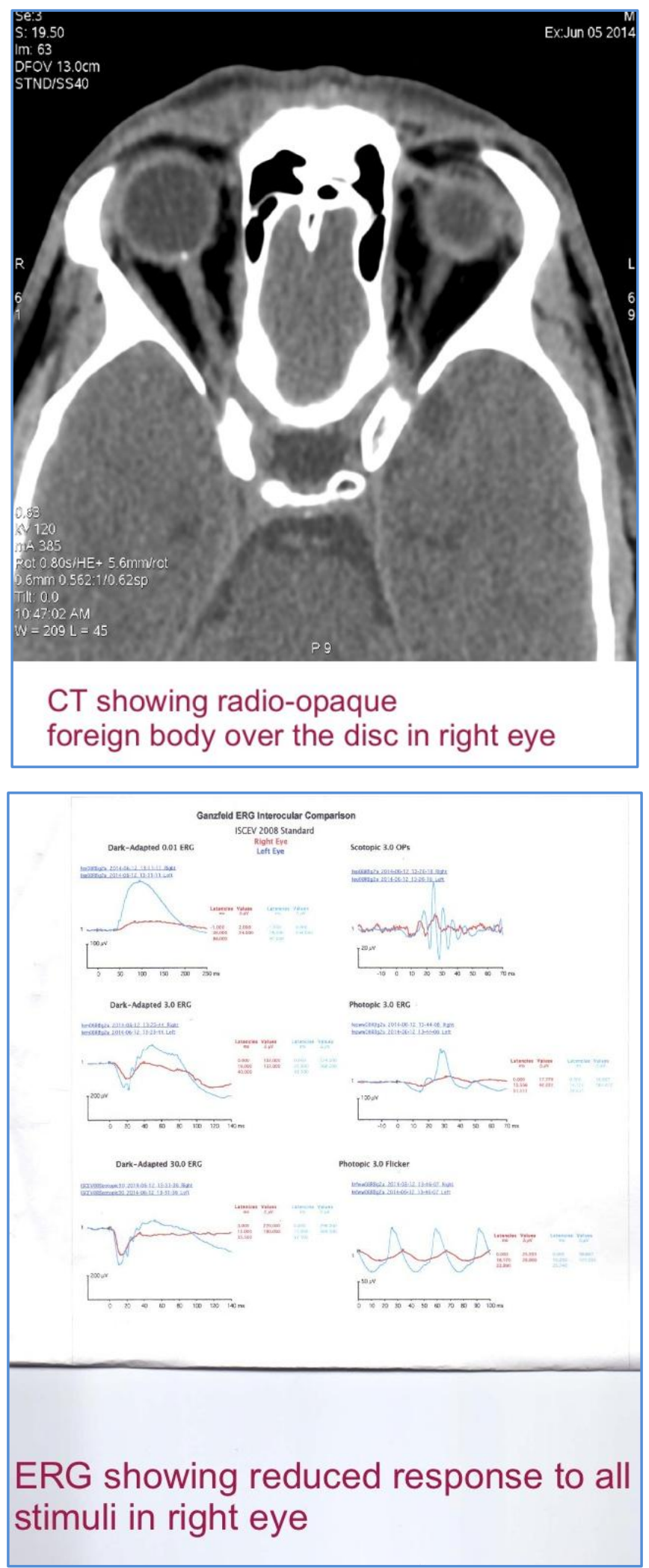

Image 1 


\section{CASE REPORT}
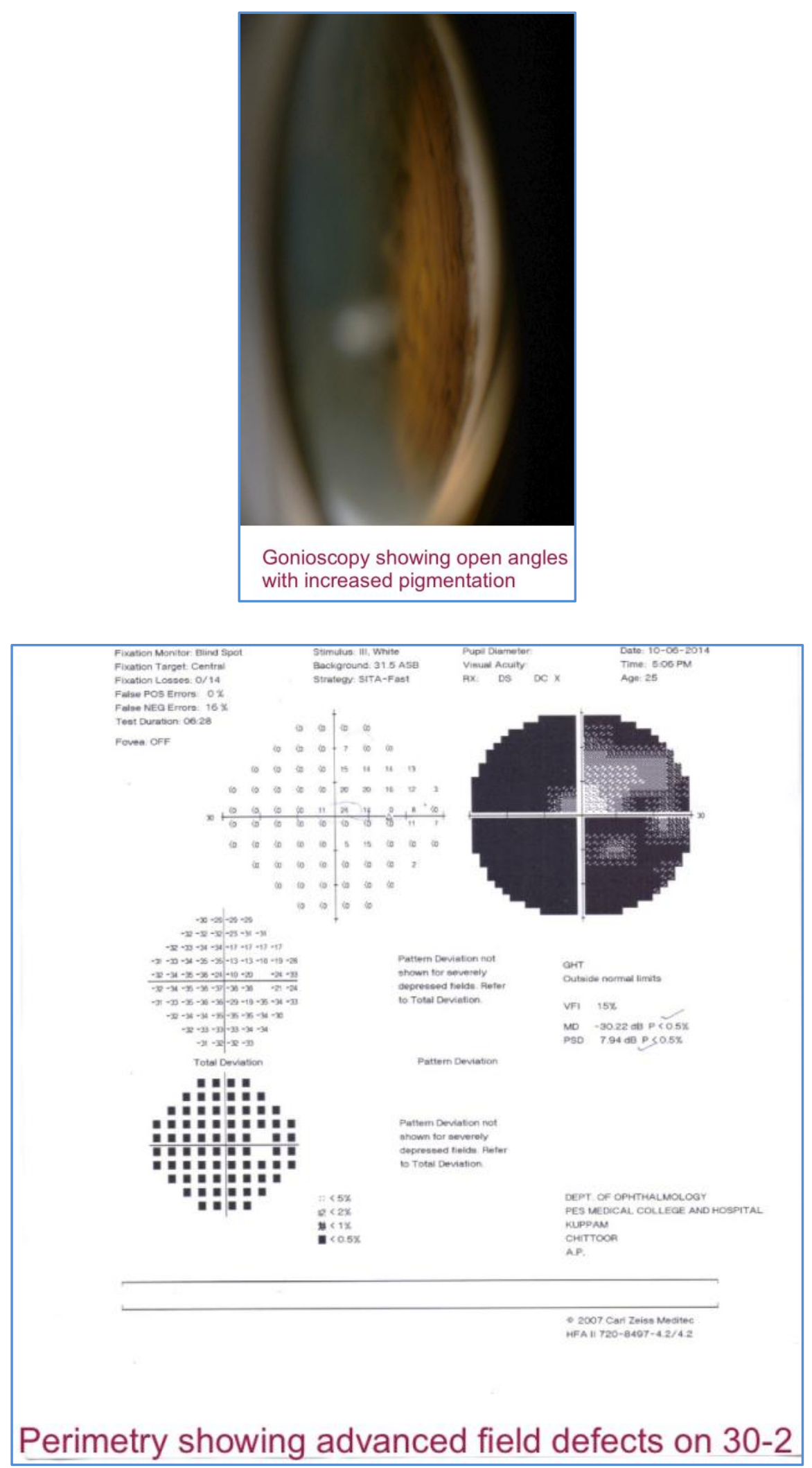

\section{Image 2}




\section{CASE REPORT}

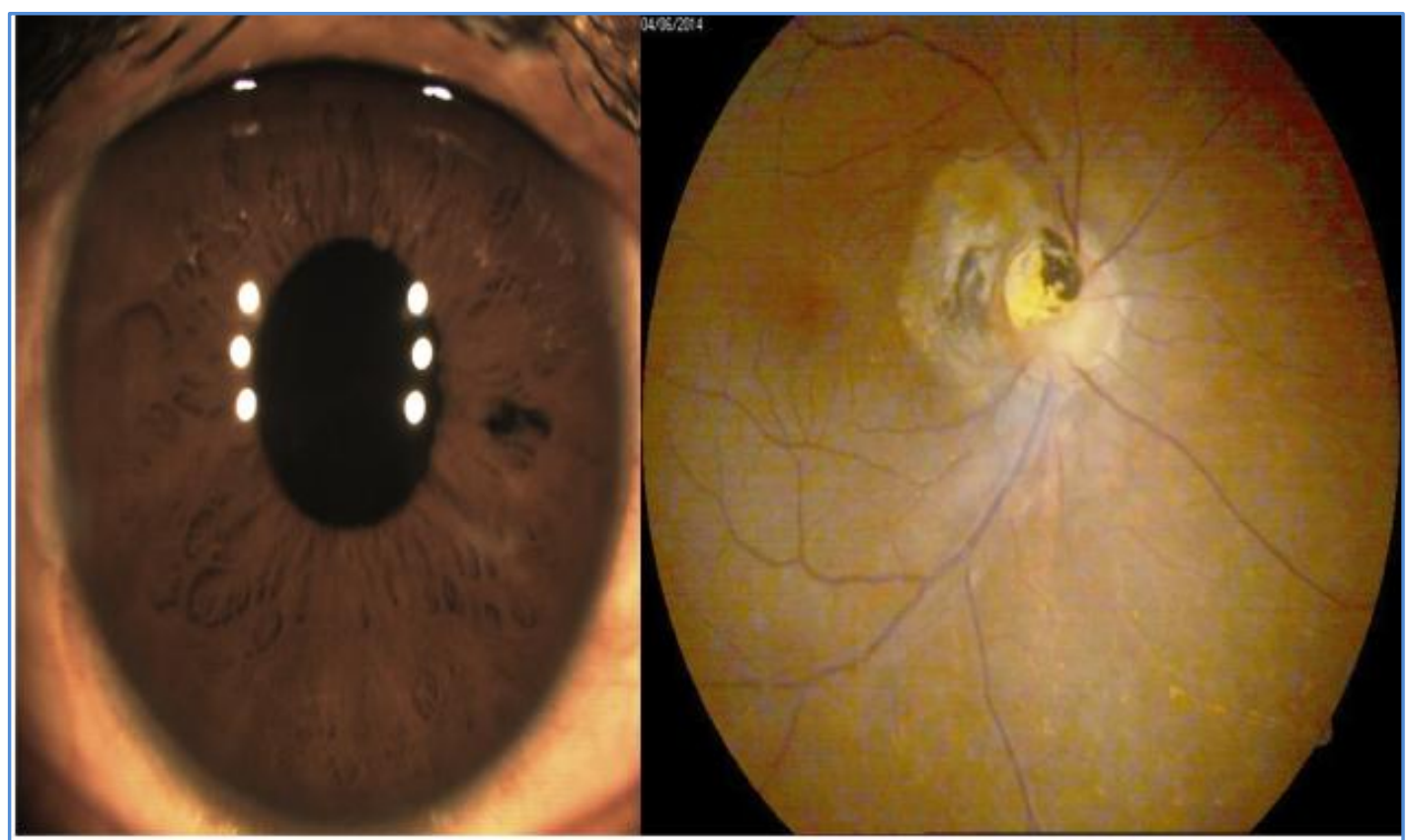

Slit lamp examination - corneal scar with Iris defect at $3^{\prime} \mathrm{O}$ clock
Fundus photograph showing foreign body over the disc with peripapillary pigmentation Optic disc pallor and attenuated vessels

\section{Image 3}
AUTHORS:
1. Chandrakant Pujar
2. Narayan M.
3. Sai Sushma
4. Prabhu
5. Padmini

\section{PARTICULARS OF CONTRIBUTORS:}

1. Assistant Professor, Department of Ophthalmology, P. E. S. Institute of Medical Sciences \& Research.

2. Professor \& HOD, Department of Ophthalmology, P. E. S. Institute of Medical Sciences \& Research.

3. Resident, Department of Ophthalmology, P. E. S. Institute of Medical Sciences \& Research.

\section{FINANCIAL OR OTHER} COMPETING INTERESTS: None
4. Resident, Department of Ophthalmology, P. E. S. Institute of Medical Sciences \& Research.

5. Resident, Department of Ophthalmology, P. E. S. Institute of Medical Sciences \& Research.

\section{NAME ADDRESS EMAIL ID OF THE CORRESPONDING AUTHOR:}

Dr. Chandrakant Pujar, Room No. 3, P. G. Quarters, P. E. S. I. M. S. R, Kuppam-517425.

E-mail: chandrakantpujari@rediffmail.com

Date of Submission: 02/01/2015.

Date of Peer Review: 03/01/2015.

Date of Acceptance: 04/02/2015.

Date of Publishing: 12/02/2015. 